\section{Assessing the Role of Food Handlers in Hepatitis A Virus Transmission — Multiple States, 2016-2019}

\author{
Megan G. Hofmeister, MD ${ }^{1}$; Monique A. Foster, MD ${ }^{1}$; \\ Martha P. Montgomery, $\mathrm{MD}^{1}$; Neil Gupta, $\mathrm{MD}^{1}$
}

The United States is experiencing person-to-person outbreaks of hepatitis $A$ in unprecedented numbers during the vaccine era (1). As of May 2020, 33 states had reported hepatitis A outbreaks involving approximately 32,500 cases, 19,800 (61\%) hospitalizations, and 320 deaths since 2016 (1). These infections are spreading primarily through close contact among persons who use drugs and persons experiencing homelessness, as well as among men who have sex with men (MSM) (2).

During these outbreaks, hepatitis A infections occurring among food handlers have raised public alarm and resulted in calls for vaccinating all food handlers, often prompting health departments to divert limited resources away from populations at risk. However, the risk for secondary transmission from hepatitis A-infected food handlers to food establishment patrons is not well understood. To characterize this risk, a novel, structured survey was developed and conducted using Research Electronic Data Capture (REDCap) (version 9.5.13; Vanderbilt University); among 30 state health departments reporting person-to-person hepatitis A outbreaks during July 1, 2016-September 13, 2019, 29 states responded $(3,4)$.

Twenty-six states $(89.7 \%)$ submitted complete information regarding secondary transmission events associated with food handlers (Table). Among 22,825 hepatitis A outbreak cases reported from these 26 states during July 1, 2016September 13, 2019, 871 (3.8\%) were among food handlers; 587 (67.4\%) hepatitis A-infected food handlers reported one or more risk factors (i.e., drug use, unstable housing or homelessness, MSM, or incarceration) during the 15-50 days before symptom onset. Associated with these 871 hepatitis A-infected food handlers were eight $(0.9 \%)$ secondary transmission events (Table), which resulted in 57 secondary cases.

Eighteen of 29 states $(62.1 \%)$ submitted complete information for public health response activities related to hepatitis Ainfected food handlers. Among 275 cases in food handlers from these 18 states, 271 (98.5\%) investigations and 63 (22.9\%) public notifications took place.

Ongoing hepatitis A outbreaks have been prolonged and costly to control (5). These study findings indicate that the risk for secondary infection from hepatitis A-infected food handlers to food establishment patrons in these outbreaks is low $(<1.0 \%)$. Therefore, public health efforts to preemptively
TABLE. Hepatitis A-infected food handlers: risk factors, secondary transmission, and public health response - multiple states, 2016-2019

\begin{tabular}{|c|c|}
\hline Characteristic (no. with available data)* & No. (\%) \\
\hline \multicolumn{2}{|l|}{ Hepatitis A-infected food handlers } \\
\hline States submitting complete information (29) & $26(89.7)$ \\
\hline Total outbreak-associated ${ }^{\dagger}$ cases & 22,825 \\
\hline Outbreak-associated cases among food handlers $(22,825)$ & $871(3.8)$ \\
\hline \multicolumn{2}{|l|}{ Risk factors among hepatitis A-infected food handlers ${ }^{\S}$} \\
\hline Drug use (injection or noninjection) (871) & $486(55.8)$ \\
\hline Unstable housing or homelessness (760) & 73 (9.6) \\
\hline Incarceration (646) & $54(8.4)$ \\
\hline Men who have sex with men (416) & $85(20.4)$ \\
\hline One or more of the above risk factors (871) & $587(67.4)$ \\
\hline \multicolumn{2}{|l|}{ Secondary transmission } \\
\hline $\begin{array}{l}\text { Secondary transmission events to food establishment } \\
\text { patrons directly attributed to a hepatitis A-infected } \\
\text { food handler**,+† (871) }\end{array}$ & $8(0.9)$ \\
\hline $\begin{array}{l}\text { Number of secondary cases directly attributed to hepatitis A } \\
\text { transmission from a hepatitis A-infected food handler to } \\
\text { food establishment patrons }\end{array}$ & 57 \\
\hline $\begin{array}{l}\text { Proportion of outbreak-associated cases attributable to } \\
\text { secondary cases among food establishment patrons } \\
(22,825)\end{array}$ & $57(0.2)$ \\
\hline \multicolumn{2}{|l|}{ Public health response } \\
\hline States submitting complete information (29) & $18(62.1)$ \\
\hline $\begin{array}{l}\text { Number of hepatitis-A infected food handler investigations } \\
\text { (275) }\end{array}$ & $271(98.5)$ \\
\hline Investigations involving public notification (275) & $63(22.9)$ \\
\hline $\begin{array}{l}\text { Investigations where postexposure prophylaxis was offered } \\
\text { to food establishment patrons (275) }\end{array}$ & $80(29.1)$ \\
\hline
\end{tabular}

* Not all states collected or reported complete data for each variable presented in the table.

${ }^{\dagger}$ Outbreak-associated status is determined at the state level in accordance with each state's outbreak case definition.

$\S$ Survey respondents were instructed to assign hepatitis A-infected food handlers to a risk category if the food handler reported the risk factor during their exposure period (i.e., the 15-50 days before first symptom onset). Individual risk factor categories are not mutually exclusive. If a hepatitis Ainfected food handler reported multiple risk factors, they were counted in each applicable category. The variables "drug use (injection or noninjection)" and "at least one of the above risk factors" were complete for 26 states, 25 of 26 states reported data for "unstable housing or homelessness" and "men who have sex with men," and 24 of 26 states reported data for "incarceration."

" Secondary transmission was defined as hepatitis A virus transmission from an infected food handler to food establishment patrons (i.e., the patron reported consuming food prepared by an infected food handler during the applicable exposure period and did not have a more likely alternative explanation for hepatitis A infection, such as drug use or homelessness).

** A transmission event was defined as a documented occurrence of secondary transmission of hepatitis A virus from an infected food handler to at least one food establishment patron.

${ }^{+\dagger}$ Among the eight discrete transmission events, six events (75\%) resulted in three or fewer secondary cases, one resulted in 16 secondary cases, and one resulted in 26 secondary cases.

vaccinate all food handlers would be ineffective at mitigating the current risk for person-to-person outbreaks. To optimize resources, health departments should assess the risk for secondary transmission of hepatitis A from infected food handlers on 
a case-by-case basis and prioritize vaccination efforts in situations where secondary transmission risk is deemed high (G).

Approximately two thirds of the hepatitis A-infected food handlers in this survey reported risk factors commonly associated with the current person-to-person outbreaks. This underscores the importance of vaccination strategies targeting the populations at highest risk (i.e., persons who use drugs, persons experiencing unstable housing or homelessness, MSM, and persons who are or were recently incarcerated) as the cornerstone of an effective public health response.

\section{Acknowledgments}

Staff members of state and local health departments in Alabama, Arizona, Arkansas, California, Colorado, Florida, Georgia, Idaho, Illinois, Indiana, Kentucky, Louisiana, Massachusetts, Michigan, Minnesota, Mississippi, Missouri, Nevada, New Hampshire, New Jersey, New Mexico, North Carolina, Ohio, South Carolina, Tennessee, Utah, Virginia, Washington, and West Virginia.

Corresponding author: Megan G. Hofmeister, lxn7@cdc.gov, 404-718-5458.

\footnotetext{
${ }^{1}$ Division of Viral Hepatitis, National Center for HIV/AIDS, Viral Hepatitis, STD, and TB Prevention, CDC.
}

All authors have completed and submitted the International Committee of Medical Journal Editors form for disclosure of potential conflicts of interest. No potential conflicts of interest were disclosed.

\section{References}

1. CDC. Widespread person-to-person outbreaks of hepatitis A across the United States. Atlanta, GA: US Department of Health and Human Services, CDC; 2020. https://www.cdc.gov/hepatitis/HepAOutbreak.

2. Foster MA, Hofmeister MG, Kupronis BA, et al. Increase in hepatitis A virus infections-Unitd States 2013-2018. MMWR Morb Mortal Wkly Rep 2019;68:413-5. https://doi.org/10.15585/mmwr.mm6818a2

3. Harris PA, Taylor R, Thielke R, Payne J, Gonzalez N, Conde JG. Research electronic data capture (REDCap) — a metadata-driven methodology and workflow process for providing translational research informatics support. J Biomed Inform 2009;42:377-81. https://doi.org/10.1016/j.jbi.2008.08.010

4. Harris PA, Taylor R, Minor BL, et al.; REDCap Consortium. The REDCap Consortium: building an international community of software platform partners. J Biomed Inform 2019;95:103208. https://doi. org/10.1016/j.jbi.2019.103208

5. Bownds L, Lindekugel R, Stepak P. Economic impact of a hepatitis A epidemic in a mid-sized urban community: the case of Spokane, Washington. J Community Health 2003;28:233-46. https://doi. org/10.1023/A:1023981924010

6. Fiore AE. Hepatitis A transmitted by food. Clin Infect Dis 2004;38:705-15. https://doi.org/10.1086/381671 